\title{
The effect of different types of mice upon muricidal behavior in the Long-Evans rat
}

\author{
B. MICHAEL THORNE and MICHAEL E. THOMPSON \\ Mississippi State University, Mississippi State, Mississippi 39762
}

\begin{abstract}
Long-Evans hooded rats are much more likely to kill wild mice than domestic mice. Several experiments were performed in an attempt to discover the primary mechanism(s) by which the two types of mice are differentiated. The discrimination was maintained despite blinding of the rats, deafening, removal of the vibrissae, altering the activity and/or the odor of the mouse, or combinations of treatments. Some evidence was obtained for a differentiation through the use of olfactory cues.
\end{abstract}

Despite the volume of research that has been generated in the past 2 decades concerning the muricidal tendencies of the rat, relatively few studies have dealt directly with the stimulus characteristics of the mouse. We became particularly concerned with the stimulus properties of the mouse following a failure to replicate a portion of a study reported by Miczek and Grossman (1972). Specifically, Miczek and Grossman found that $100 \%$ of rats with septal damage killed mice, while Latham and Thorne (1974) failed to observe an increase after similar lesions in the same rat strain.

In an exchange of correspondence with S. P. Cirossman (personal communication, June 1974), the observation was made that a difference in the type of mouse employed in the tests might account for the failure to replicate. In the Miczek and Grossman (1972) experiment, rather aggressive pigmented mice were employed, while we had used very docile albino mice for the killing tests. On the basis of this difference, and because of the lack of experimentation in the area, we decided to compare the rate of killing of nonaggressive mice with that of a more aggressive variety. In order to amplify any difference that might exist, the comparison was made between mice differing in as many characteristics as possible from the domestic albino strain in our laboratory, i.e., freshly trapped field mice (Mus musculus) were used.

\section{EXPERIMENT I}

\begin{abstract}
Method
Subjects. The mice used in this and in subsequent studies were either domestic albino mice of unknown genetic origin or mice which were trapped live in the vicinity of a swine farm south of the Mississippi State University campus.
\end{abstract}

The authors would like to thank Keith Rager for his assistance in trapping mice, and the Department of Zoology for lending us the traps. Reprint requests should be sent to: B. Michael Thorne, P.O. Drawer PF, Mississippi State, MS 39762.
Although several different species of rodents were captured (voles, small rats, shrews), only the mice were retained. Comparison with the reference collection of the Zoology Department revealed them to be common house mice (Mus musculus). All mice, whether domestic or wild, were multiply housed until used in testing.

Because of the small size of the wild mice in comparison with the domestic, several of them were able to escape by squeezing through the grid floor or front of the rat's cage during the muricidal test. Mice that escaped were subsequently recaptured and released outside the building housing the laboratory.

The rats tested for muricidal tendencies were 47 Long-Evans adults (29 females, 18 males) derived from breeding stock originally obtained from Research Animals, Inc., Braddock, Pennsylvania. All rats in this and subsequent studies were at least 60 days old at the time of testing. Since five of the wild mice escaped during the initial muricidal test, data is reported for 42 animals, 27 females and 15 males. Of the 42 subjects, 24 were initially exposed to a wild mouse (WM), while 18 were tested originally with a domestic mouse (DM). All except five of the females were subsequently tested with the opposite type of mouse. Two of the WM escaped, leaving an $\mathrm{N}$ of 20 for the second mouse-killing test.

Rats were multiply housed from weaning until at least $24 \mathrm{~h}$ prior to testing, at which time they were singly housed in hanging cages measuring 17.78 by 25.40 by $17.78 \mathrm{~cm}$. Ad-lib food and water conditions were maintained, and the animals were not gentled prior to the muricidal tests. The colony was kept under a light-dark cycle of approximately $10 \mathrm{~h}$ on and $14 \mathrm{~h}$ off.

Procedure. For the initial mouse-killing test, either a freshly caught WM or a DM was placed into the home cage of each subject. All testing began during the light portion of the rat's light-dark cycle. The rat's reaction to the mouse was observed for $20 \mathrm{~min}$, and, if killing occurred, the latency was recorded. At the end of $24 \mathrm{~h}$, the test was terminated and a latency of $24 \mathrm{~h}$ was recorded for any mice killed after the 20 -min observation period. At this time, any live mice and the remains of any dead mice were removed from the cage.

All excent five of the females were subsequently given a test with the opposite type of mouse from the initial test. This test was conducted in the same manner as the first test and was administered within 3 days of the initial test.

\section{Results and Discussion}

Response topography. In almost every instance, the WM displayed a burst of activity when placed into the rat's cage, frequently bumping the rat in its 
Table 1

Number of Killers and Latency Scores in Unaltered Rats Tested with WM and DM

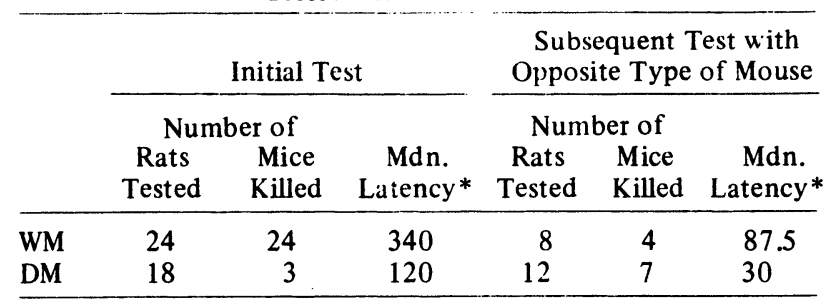

*Median latencies are express in seconds.

leaps about the cage. Many rats began pursuing the mouse at this time, attacking the animal more or less efficiently, depending upon the position of and postures assumed by the WM. If cornered, the WM would usually assume a boxing, defensivetype posture which often temporarily frustrated the rat. Mice were generally killed by bites to the head, neck, or upper back. DM behaved much like WM once the rat began at attack; however, the animals seemed much less reactive prior to attack.

Initial test. In this experiment, the results from male and female rats were analyzed separately and compared. Since the comparison revealed no differences in either rate of killing or latency to kill, in this and subsequent studies the data from males and females are combined. The results of the initial test were unequivocal and are summarized in Table 1. All WM were killed, while only 3 of $18 \mathrm{DM}$ received a similar fate. Because of the magnitude of the effect, a statistical test would have been superfluous. A statistical test comparing latency to kill was not performed because of the small number of rats which killed DM.

Subsequent test. When testing with a DM followed a test with a WM, 7 of 12 rats killed the DM. While this is obviously less than the number killing WM on the first test, the outcome was still significantly different from the number killing DM on the initial test (Fisher exact probability test, $p=.024$ ). The latency measure revealed that six of the seven rats that killed did so with either the same or a shorter latency than exhibited originally. Additionally, all five of the DM nonkillers had 24-h latencies on the previous test with the WM.

Of the eight animals initially tested with a DM that were subsequently tested with a WM, four killed. Of these four, however, two had killed DM previously. In both cases, the WM were killed with a shorter latency.

The results of the second killing test which exposed rats to the opposite type of mouse from that encountered initially are in agreement with previous research which has shown that killing becomes more rapid and stable with repeated testing (Myer, 1971).
The results from the rats initially tested with WM supports previous evidence that the tendency to kill mice is present in all rats, albeit with a different threshold in each (e.g., Vogel \& Leaf, 1972). It is obvious that the WM provides an unusually powerful stimulus for elicitation of the muricidal response. Since the WM employed differed in several observable characteristics from the albino DM, the remaining experiments in this paper deal with attempts to discover the property or properties by which rats differentiate the mice.

\section{EXPERIMENT II}

In Experiment I, the primary behavioral characteristic which differentiated WM and DM appeared to be a greatly lowered threshold of stimulus reactivity. That is, WM almost invariably engaged in vigorous escape behavior when approached by a rat and made many more rapid darts about the cage than DM. Since previous research has shown activity of the mouse to be an important variable for eliciting attack (Van Hemel \& Colucci, 1973), an attempt was made to equate WM and DM on the activity variable.

\section{Method}

Subjects. The subjects were 38 naive Long-Evans adult rats (24 females, 14 males) acquired and maintained in the same manner as in Experiment $I$. Of the 38 rats, 15 were tesied with tranquilized WM, 13 with tranquilized DM, and 10 with untranquilized WM. In addition, the data from the 18 subjects from Experiment I tested with DM were used in comparisons with results from this experiment.

Procedure. Twenty-eight mice (15 WM and $13 \mathrm{DM})$ were given a small dose of a minor tranquilizer (Valium, .08 cc at $1 \mathrm{mg} / \mathrm{cc}$ ) and placed into a rat's cage approximately $10 \mathrm{~min}$ later. The drug and dosage were chosen on the basis of a pilot study to provide a reduction in stimulus reactivity without complete locomotor ataxia. In addition, 10 rats received unaltered WM.

The length of the killing test was $30 \mathrm{~min}$, with continual observation throughout. The length of the test was selected in order to provide enough time for the majority of killers to display muricidal tendencies but insufficient time for full recovery from the tranquilizer to occur. Because the length of the test differed in Experiments I and II, an additional group of rats was necessary to determine the effect of the shorter test on the number of killers of WM. The rats tested with DM in Experiment I were used for comparison in this experiment since all killed with a latency of less than $30 \mathrm{~min}$.

\section{Results and Discussion}

With the addition of the tranquilizer in both types of mouse, the behavior of each appeared quite similar. Thus, both the WM and DM moved rather slowly about the cage, or in cases where the dosage had a slightly greater effect, stayed in one place until stimulated by the rat.

The number of rats killing in each group and their mean latencies are shown in Table 2. Although several tranquilized WM were not killed, statistical 
comparisons indicated results similar to Experiment $\mathrm{I}$. Thus, the rate of killing of tranquilized DM and WM did not differ from that of the untranquilized mice of the same type. More tranquilized WM were killed than tranquilized DM, however $(\mathrm{p}=.05$, Fisher test). Although the average killing latency exhibited by rats tested with tranquilized DM was considerably longer than that exhibited by rats tested with unaltered mice, because of the small $\mathbf{N}$ and the large amount of variability, the difference was not significant.

Taking a conservative point of view in a statistical sense, the results of this study indicate that the differential reactivity level of the WM is not the primary cue by which they are distinguished from the DM. However, the slight reduction in the rate of killing may indicate that reactivity (and activity) is of importance although probably in conjunction with some other mechanism(s).

Since a slight, but not significant, reduction in the killing of WM was observed in this experiment, a question might be raised concerning the possible effect of different levels of tranquilization. That is, if the WM received larger amounts of Valium, would a further reduction in the rate of killing be observed? Again. our attempt in the study was to equate the level of activity in the WM and DM, and in this we were reasonably successful. Additionally, the study by Van Hemel and Colucci (1973) provides evidence concerning the effect of complete tranquilization on the rate of mouse killing. The authors found that completely unconscious mice were almost always killed by rats, but with an increased latency. We inadvertently replicated this effect in a pilot study by giving some DM a slightly larger dose of tranquilizer than was given to a group of WM (.1 cc instead of $.08 \mathrm{cc})$. Almost all of the completely unconscious DM were killed. Thus, the evidence indicates that larger doses of Valium would result in higher rates of killing rather than lower.

\section{EXPERIMENT III}

Because WM differ from DM on a variety of different sensory dimensions, the present study was designed to determine whether the differentiation exhibited by rats is a function of differing visual characteristics, differing vocalizations, or differing textural configuration that might be detectable through the vibrissae.

\footnotetext{
Method

Subjects. The subjects were 38 naive Long-Evans rats ( 25 males, $13 \mathrm{females}$. All were derived and maintained as in Experiment I. Three WM escaped, one rat died, and two rats were eliminated because of incomplete sensory loss (audition), leaving a total of
}

Table 2

Number of Killers and Latency Scores in Rats Tested with Tranquilized WM or DM or Unaltered WM

\begin{tabular}{lccc}
\hline & \multicolumn{2}{c}{ Number of } & \\
& $\begin{array}{c}\text { Rats } \\
\text { Tested }\end{array}$ & $\begin{array}{c}\text { Mice } \\
\text { Killed }\end{array}$ & $\begin{array}{c}\text { Average } \\
\text { Latency* }\end{array}$ \\
\hline Tranquilized WM & 15 & 10 & 325.4 \\
Tranquilized DM & 13 & 3 & 620 \\
Unaltered WM & 10 & 9 & 379.4 \\
\hline
\end{tabular}

*Average latencies are reported in seconds.

32 rats on which data are reported. Of the 32 rats, 10 were enucleated, 12 deafened, and 10 had their vibrissae shaved. Within each treatment condition, five rats were tested with WM and the remainder with DM.

Surgical procedures. All surgical procedures were performed under chloral hydrate anesthesia and clean, but not aseptic, conditions. Animals subjected to enucleation were tested 2 days postoperatively, rats with auditory damage were tested from 4 to 8 days postoperatively, and animals with their vibrissae removed were tested either on the day of the operation or on the following day.

Enucleation. The tips of blunt surgical scissors were pressed around the orbit of the eye, resulting in extrusion of the eyeball. The optic nerve and eye-muscle attachments were cut, and a cotton swab that had been soaked in alcohol was applied to the resulting lesion.

Deafening. A small cut was made below the rat's ear to expose the auditory meatus. A wire probe was inserted approximately $3 \mathrm{~mm}$ into the canal and rotated. The eardrum was destroyed together with the bones of the middle ear. All deafened rats were tested prior to assessment of muricidal tendencies to determine their reaction to a loud noise. A startle reaction was exhibited by two rats who were eliminated from the study.

Shaving the vibrissae. Thor and Ghiselli (1975b) have reported that shaving the vibrissae is just as effective as anesthetizing the vibrissal pads with lidocaine in suppressing irritable fighting in rats and retains its effect over a greater length of time. Thus, we lightly anesthetized 13 rats and shaved their vibrissae as completely as possible with electric clippers. During the test, three WM escaped, leaving an $\mathrm{N}$ of 10.

Procedure. All rats were given 24-h tests with continual observation during the first $20 \mathrm{~min}$. Latency scores were recorded as in the previous experiments.

\section{Results and Discussion}

The killing response exhibited by enucleated or deafened rats was indistinguishable from that described in Experiment I. Most of the rats that killed after their vibrissae were removed did so after the end of the 20-min observation period. Two animals killed within the observation period, however, and both displayed unusual response topography. Specifically, one of the rats bit the mouse almost everywhere on its body and proceeded to eat one of its hindlimbs prior to its death. The other rat killed the mouse almost as soon as it was placed in the cage with two bites to the back and thereafter showed no interest in it.

None of the sensory manipulations employed in this study affected the rate of killing of WM. The results are summarized in Table 3 and re- 
Table 3

Number of Mice Killed and Latency Scores by Blinded, Deafened, or Devibrissaed Rats Tested with Either WM or DM

\begin{tabular}{|c|c|c|c|c|c|c|}
\hline \multirow[b]{2}{*}{ Treatment } & \multicolumn{3}{|c|}{ Tested with WM } & \multicolumn{3}{|c|}{ Tested with DM } \\
\hline & $\begin{array}{l}\text { Nur } \\
\text { Rats Tested }\end{array}$ & $\begin{array}{l}\mathrm{r} \text { of } \\
\text { Mice Killed }\end{array}$ & $\begin{array}{l}\text { Median } \\
\text { Latency }\end{array}$ & $\begin{array}{c}\text { Nun } \\
\text { Rats Tested }\end{array}$ & $\begin{array}{l}\text { of } \\
\text { Mice Killed }\end{array}$ & $\begin{array}{l}\text { Median } \\
\text { Latency }\end{array}$ \\
\hline Enucleated rats & 5 & 5 & $420 \mathrm{sec}$ & 5 & 1 & $500 \mathrm{sec}$ \\
\hline Deafened rats & 5 & 5 & $310 \mathrm{sec}$ & 7 & 5 & $24 \mathrm{~h}$ \\
\hline Devibrissaed rats & 5 & 5 & $24 \mathrm{~h}$ & 5 & 1 & $24 \mathrm{~h}$ \\
\hline
\end{tabular}

veal that all WM were killed. Additionally, removal of either the eyes or the vibrissae had no effect upon the rate of killing of DM. Deafening, however, resulted in a significant increase in the rate of killing of DM when the results of the present study were compared with rats initially tested with DM in Experiment $I(p=.017$, Fisher test). Obviously, no difference in the rate of killing of WM and DM was observed in the deafened rats.

Despite the fact that three of five rats without vibrissae failed to kill a WM within the 20-min observation period, a comparison with the data from normal rats in Experiment I revealed no significant difference in the latency scores. However, a similar comparison between deafened rats tested with WM or with DM revealed a significant difference in the latency siores $(p=.0238$, Fisher test on a 2 by 2 table with latencie, dichotomized into those less than $20 \mathrm{~min}$ and those greater than $20 \mathrm{~min}$ ).

The results of the present experiment agree with most previous research in demonstrating that vision and the vibrissal organs play little role in the rate of mouse killing by the rat (Bugbee \& Eichelman, 1972; Karli, 1961; Mast, Blanchard, \& Matsumoto, 1974).

Evidence of the role of the vibrissae in the production of the killing response may be found in Gregoire and Smith (1975). Gregoire and Smith employed a technique which allows more complete deafferentation of the vibrissae than either shaving them or injecting a local anesthetic-sectioning the infraorbital nerve. Rats treated in this fashion were frequently unable to kill mice because of poorly aimed bites but exhibited greater aggression in terms of frequency of biting. In the present study, the fact that three of the five animals received latency scores of $24 \mathrm{~h}$ indicates the importance of the vibrissae in the proper orientation of the attack.

Unlike previous reports, we found a significant increase in the killing of DM after deafening. The technique we used to deafen our rats was modeled after that reported in Mast et al. (1974), who reported that none of their deafened animals killed. Study of Table 1 in Mast et al. revealed, however, that two of seven deafened rats killed mice, and when this result is compared with their control data, the result approaches significance $(\mathrm{p}=.083$, Fisher test).

One possible explanation for the observed increase in the killing of DM after deafening is that the procedure used to deafen the animals causes a relatively long-lasting pain and that such killing is basically pain-elicited or irritable aggression. There are several arguments against this explanation, however. First, at the time of testing for residual auditory capacity, the affected rats did not appear hyperirritable. Second, deafened rats were given up to 8 days to recover from the operation. Third, most of the killers took a relatively long time to kill the mice, which would argue against an irritability effect. Finally, a later attempt to replicate the increase in killing of DM by deafened rats was unsuccessful, indicating sampling error in the present study.

In summary, in terms of the rate of killing, blinding or removing the vibrissae had no effect on the rat's ability to differentiate between WM and DM. Deafened rats failed to differentiate WM and DM when only the rate of killing was considered but took significantly longer to kill DM.

\section{EXPERIMENT IV}

Karli (1961) concluded that no single sensory mechanism was of primary importance in the release of the rat's killing response since rats continued to kill despite the combined absence of olfactory, visual, and auditory information. It is possible, however, that this conclusion is primarily a function of the methodology used by Karli and is not generally applicable.

Two major criticisms of Karli's (1961) method may severely delimit the generality of his conclusions. The first is that he tested experienced killers rather than naive. There is a wealth of data from ethology and comparative psychology to indicate that a complex, stereotyped pattern of behavior may initially be triggered by only one or a few aspects of a total sensory situation, but that learning takes place and it perfects the response and brings it under multisensory control (e.g., see Hailman, 1969, for a discussion of the role of 
learning in the development of instinctual behavior). The decline in sexual behavior in mammals following castration is also relevant since it is much more variable in experienced animals than in naive (e.g., Aronson, 1965). Thus, it is entirely possible that killing by experienced rats is elicited by a variety of sensory cues from the mouse and that elimination of any one cue or of several would not prevent the response from occurring.

A second observation which may limit the generality of Karli's (1961) results is that bulbectomy was used to eliminate the use of olfactory cues. Since it has been demonstrated repeatedly that olfactory bulb removal increases mouse killing by rats (e.g., Bandler \& Chi, 1972; Malick, 1970; Thorne, Aaron, \& Latham, 1973, 1974), it is certainly probable that any experimental manipulation involving such lesions will not decrease the incidence of killing.

Primarily because of the increases in emotionality which reportedly follow bulbectomy in the rat and the lack of such changes when other techniques are used to produce anosmia, most current researchers espouse the belief in a dual role for the bulbs, i.e., a primarily sensory role and a role which cannot be explained in terms of sensory loss (e.g., Alberts \& Friedman, 1972; Cain, 1974; Spector \& Hull, 1972). In almost all of the recent studies in which the effects of bulbectomy have been compared with effects produced by peripheral anosmia, the technique used to produce anosmia has been the infusion of zinc sulfate over the olfactory mucosa (Alberts \& Galef, 1971). Unfortunately, Sieck and Baumbach (1974) reported that complete anosmia is rarely produced by zinc sulfate treatment and independent tests of anosmia may be affected by the systemic effects of the treatment. Additional evidence for the lack of effectiveness of the zinc sulphate technique may be found in Mayer and Rosenblatt (1975), who found evidence for hyposmia but not anosmia in treated rats tested with a potent olfactory stimulus. Viewed from this perspective, the frequently reported failure to find behavioral differences between control animals and animals with zinc sulfate treatment may reflect the failure of the technique to render animals anosmic rather than a nonolfactory role for the olfactory bulbs.

Because the rat is a macrosmatic animal, and Experiments II and III had failed to decrease the rate of killing of WM, the present study was designed to investigate the possibility that rats differentiate WM and DM on the basis of odor cues. Since neither bulbectomy nor zinc sulfate treatment seem to be appropriate methods for rendering rats anosmic, we elected to approach the task from another perspective, i.e., by altering or masking the odor of the mouse.
Table 4

Number of Killers and Latency Scores in Rats Tested with Deodorized WM or DM

\begin{tabular}{|c|c|c|c|}
\hline & \multicolumn{2}{|c|}{ Number of } & \multirow{2}{*}{$\begin{array}{l}\text { Mdn Latency } \\
\text { to kill* }\end{array}$} \\
\hline & Rats Tested & Mice Killed & \\
\hline WM & 10 & 5 & 45 \\
\hline DM & 10 & 8 & 350 \\
\hline
\end{tabular}

*Median latencies are expressed in seconds.

\section{Method}

Subjects. The subjects were 20 naive adult Long-Evans rats, $11^{\circ}$ females and 9 males. All subjects were acquired and maintained as in the previous experiments. Half of the rats were tested for muricidal tendencies with WM, and the other half with DM. All mice were sprayed with a commercial deodorant, Unscented Right Guard.

Procedure. Shortly before the muricidal test, the mice were liberally sprayed with the deodorant in a different room from the one in which the test was conducted. Each deodorized mouse was then placed into the cage with a rat, and continual observations were made for $30 \mathrm{~min}$, at which time the test was terminated. The data from tests with unaltered WM in Experiment II and from unaltered DM in Experiment I were compared with the results from this experiment.

\section{Results and Discussion}

In terms of rate of killing, there was a significant increase in the number of DM killed after being sprayed with deodorant. The rate at which deodorized WM were killed was not significantly different from that exhibited by rats tested with deodorized DM and was not different from that of rats tested with unaltered WM although the probability was close to the .05 level $(p=.07$, Fisher test). The number of killers in each group and the median killing latencies are shown in Table 4.

The result of a comparison of latency scores for rats tested with deodorized WM or DM resulted in a value close to that required for significance (Mann-Whitney $U=8.5, .047<p<.064$ ). Thus, although slightly more deodorized DM than WM were killed, there was a trend toward more rapid killing of the WM.

There are at least two ways to interpret the data from this experiment. One way involves the assumption that the reduction in killing of WM after they had been sprayed with deodorant was a meaningful reduction although the comparison with unaltered WM did not quite result in a probability meeting acceptable statistical standards. If we accept this assumption, then we can conclude that the natural odor of the WM elicits attack by the rat and that altering the odor reduces the rate of attack. The increase in killing rate of deodorized DM may be explained by assuming that normally the odor of the DM inhibits attack and that altering this odor removes the inhibition.

A more plausible explanation, both because it involves fewer assumptions and because of the results 
Table 5

Number of Tranquilized, Deodorized WM and DM Killed and the Median

\begin{tabular}{|c|c|c|c|}
\hline & \multicolumn{2}{|c|}{ Number of } & \multirow{2}{*}{$\begin{array}{c}\text { Mdn Killing } \\
\text { Latencies }\end{array}$} \\
\hline & Rats Tested & Mice Killed & \\
\hline WM & 10 & 9 & 120 \\
\hline DM & 10 & 9 & 540 \\
\hline
\end{tabular}

*Median latencies are expressed in seconds.

of a subsequent experiment, is that the deodorant did not significantly decrease the rate of killing of WM but did result in an increase in killing of DM because the odor of the deodorant elicits attack. It is possible that results from other studies in which natural odors have been masked with foreign substances may be amenable to similar interpretation. For example, Myer (1964) found that rats which normally killed mice but did not kill rat pups killed all rat pups after they had been coated with oil of lavender. Myer assumed that the perfume masked an inhibiting odor. It is equally plausible that oil of lavender and many other odors elicit attack behavior in rats regardless of other properties of the object to which they are applied. We have observed, for example, that most rats attempt to bite cotton swabs that have been soaked in after-shave lotion.

At any rate, the results from this experiment provide some evidence for the importance of olfactory cues in the eliciting of attack behavior since altering the odor of DM resulted in an increase in killing. Unfortunately, the results tell us little about the cue(s) by which DM and WM are distinguished.

\section{EXPERIMENT V}

Since two of our previous experimental manipulations had resulted in nonsignificant decreases in the rate of killing of WM, the present study was designed to test the effect of combining the two treatments, i.e., reducing activity and deodorizing the mice.

\section{Method}

Subjects. The subjects were 20 Long-Evans rats similiar to those used in previous studies. There were 10 males and $i 0$ females divided equally between the two treatment groups. Half of the rats were given killing tests with tranquilized, deodorized WM, while the other half were tested with similarly prepared DM. Groups for comparison tested with unaltered DM and WM were laken from Experiments I and II

Procedure. All mice were injected with $.08 \mathrm{cc}$ Valium and, after approximately $10 \mathrm{~min}$, were sprayed with Unscented Right Guard. They were then placed into the front of the rat's cage and observed continuously for $30 \mathrm{~min}$.

\section{Results and Discussion}

The behavior of both the rats and the mice was similar to that observed in Experiment II. The killing results were both unexpected and unequivocal; only one treated DM and one WM survived the test. Thus, the results were identical for the treated DM and WM and were also the same as the results for the unaltered WM in Experiment II. The treated DM were obviously killed at a higher rate than were the unaltered DM in Experiment $I(p=.0003$, Fisher test). The number of mice killed and the median latency scores are shown in Table 5.

Although tranquilized and deodorized WM and DM were not differentiated in terms of how many of each were killed, a nonparametric comparison of latency scores revealed that the WM were killed more quickly (Mann-Whitney $U=19, \mathrm{p}<.05$, onetailed test).

The tremendous increase in the rate of killing of DM observed both in this experiment and in Experiment IV led us to suspect that the olfactory manipulation we employed was not an adequate test of whether or not WM and DM are differentiated by odor. Rather, it appears that we have primarily added an odor to each type of mouse which elicits attack.

Despite the lack of difference in the rate of killing of DM and WM after being deodorized or deodorized and tranquilized, WM were killed more rapidly than DM. Thus, they are still differentiated in the presumed absence of differential activity and/or odor cues. Of course, the rats could be differentating the mice on the basis of different visual, auditory, or, perhaps, tactile cues, although these mechanisms did not appear to be of major importance in Experiment III. A further possibility is that the normal odor of the WM might combine in some unknown way with the deodorant to produce an odor which could be differentiated by rats from that emitted by the deodorized DM.

\section{EXPERIMENT VI}

In addition to spraying mice with deodorant as a test of the olfactory variable, two other experiments were performed, one of which will be discussed informally and the other in some detail. The first of the two experiments was based on a technique employed by Myer (1964) in which mice and rat pups were placed in either sealed or perforated plastic bags. The test animals were then presented to experienced killer rats in order to determine whether or not the rats were utilizing odor cues to differentiate the mice from the rat pups. One methodological difficulty Myer encountered was that sealed bags were often opened by the rats, which of course rendered the test meaningless since odor cues were immediately available.

In an attempt to overcome the problem Myer (1964) reported, we gave 19 rats repeated habituation 
sessions with the plastic bags prior to presenting them with bags containing mice. Thus, all rats were exposed to the bags two or three times daily, $30 \mathrm{~min} /$ exposure, for 5 days. At the end of this time, 11 rats were presented with tranquilized WM in bags with holes, while eight were given tranquilized WM in bags without holes. Three mice were killed in each condition, which would argue against the use of olfactory cues to differentiate WM and DM. However, it was apparent from observing the rats that most of the ones that killed experienced a great deal of difficulty organizing and orienting their attack to the plastic bags. Additionally, at least five of eight rats tested with mice in airtight bags opened the bags prior to the end of the $30-\mathrm{min}$ test. This would negate any conclusions drawn from the test.

Myer (1964) reported that rats which did not kill rat pups in sealed containers often appeared distracted by the container. In our study, the distraction and consequent lack of killing was undoubtedly greater because the rats tested were naive.

Another attempt we made to investigate olfactory mechanisms involved keeping WM in the laboratory for a period of time prior to using them in a test. The purpose of this procedure was to expose them to the colony odor and to force them to acquire any odor that might be imparted from eating standard Lab Chow. The hypothesis we tested was that DM are less likely to be killed because their odor is similar to that of the rat. The prediction was that WM that were kept in the laboratory for a period of time prior to testing would be less likely to be killed than freshly captured animals.

\footnotetext{
Method

Subjects. The subjects were 20 naive adult Long-Evans rats. Since three mice escaped during testing, the final $\mathrm{N}$ was 17 . with 10 females and 7 males. The rats were housed and maintained as in the previous studies. The WM were kept in the colony housing and testing room in hanging cages that were slightly modified in an attempt to prevent escape. Although a few of the WM were used in tests after approximately 2 weeks in the laboratory, the majority were kept in the laboratory for at least 3 weeks prior to testing.

Procedure. The muricidal tests were conducted in a manner identical to Experiment I, i.e., 24-h test with $20 \mathrm{~min}$ of continuous ohservation. Since the tests were performed in the same manner as in Experiment I, the data from Experiment I were compared with the present results.
}

\section{Results and Discussion}

Although most of the WM had spent at least 3 weeks in the laboratory, they had lost little of their exaggerated reactivity (wildness) and were treated by the rats as if they were freshly caught animals. Of 17 mice tested, 15 were killed, with a median latency of $450 \mathrm{sec}$. Thus, there was no difference in the number of WM killed or in the latency with which they were killed in this study and in Experiment I. There were obviously more WM killed in this study than DM killed in Experiment $I\left(\chi^{2}=13.94, p<.001\right)$.

The results of the present study indicate that maintenance in the colony room and eating standard Lab Chow do not make a DM out of a WM, unless it takes more than 3 weeks. It is possible, of course, that a longer period of adaptation to laboratory conditions might result in a decrease in the rate of killing of WM. Since there was no hint of a decrease in the results of this study, we would tend to discount this possibility.

\section{EXPERIMENT VII}

In previous attempts to manipulate olfactory cues (i.e., Experiments IV, V, and, to a limited extent, VI), we concluded that our primary difficulty was in the methodology. If the report by Sieck and Baumbach (1974) is accurate, then all present methodologies for rendering rats anosmic are suspect since there may be either some. residual olfactory ability present or behavioral changes consequent to the technique may interact with the behavior under investigation. Any residual olfactory ability in supposedly anosmic rats would make the results of muricidal tests with WM meaningless, since we have demonstrated that the cue or cues used by rats to differentiate WM and DM are very potent. Thus, a rat might fail to achieve a criterion on an independent test of olfactory ability after some procedure such as bulbectomy or zinc sulfate treatment, yet still be able to perceive a difference between the odors of WM and DM.

In a book concerning research methodology, Sidman (1960) discussed a technique called "replication by affirming the consequent." The present experiment involves a variation of this technique. Specifically, if we assume that rats are differentiating WM and DM primarily on the basis of olfactory cues, then if all other major sensory avenues are eliminated in the same animal, it should still be able to make the distinction.

\section{Method}

Subjects. The subjects were 10 naive adult Long-Evans female rats, maintained similarly to rats in previous experiments.

Procedure. All rats were subjected to enucleation, destruction of the tympanic membrane and ossicles, and shaving of the vibrissae prior to being tested with either WM (five rats) or DM (five rats). Blinding and deafening were accomplished in one operation with the animal under deep chloral hydrate anesthesia. Following a 4-day recovery period, the unanesthetized rats had their vibrissae shaved and were given the 24-h muricidal test with 20 min observation approximately $3 \mathrm{~h}$ later. Surgical procedures were performed as in Experiment III.

\section{Results and Discussion}

All rats appeared to be disorganized and clumsy during the 20-min observation period primarily because they had little opportunity to adjust to 
the loss of the vibrissae. Despite the lack of significant activity during the observation period, all WM were killed (and assigned 24-h latencies), while none of the DM were killed. This difference is highly significant $(\mathrm{p}=.004$, Fisher test). The difference in latency scores between this study and Experiment I was significant $(\mathrm{p}=.004$, Fisher test) when data was dichotomized into animals killing in less than $20 \mathrm{~min}$ and those taking longer than 20 min to kill.

The results of this experiment indicate that, despite the loss of three major sensory mechanisms, rats continue to differentiate between WM and DM. According to Sidman (1960), the result we obtained would not prove the original assumption, i.e., that olfaction is the primary mechanism for the discrimination, but would add an increment of validity to it. Many further results of this type would be necessary for us to begin to have any certainty that the original assumption was true.

The long latency to kill seen in this study is quite similar to that seen in rats in Experiment III. It can be explained in terms of a deficit in the execution of the attack response since bites seem to be poorly aimed due to lack of feedback from the perioral region. The increased latency corroborates a report by Thor and Ghiselli (1975a), who found that local anesthesia of the vibrissae resulted in increased latency and an initial failure to kill in some experienced killer rats.

\section{DISCUSSION}

One major result from the series of experiments reported in this paper is the indication that the type of mouse used to test muricidal tendencies in the rat is important. Previous research has generally found that the type of mouse used is of little consequence. For example, Karii (1956) reported that the sex of the mouse did not influence the rate of killing, and he used males and females interchangeably thereafter. Similarly, Knutson (1973, p. 269) found that the rate of mouse killing was influenced neither by the sex of the mouse nor by whether it was pigmented. Kreiskott (1969) suggested, however, that the behavior, particularly the aggressiveness, of the mouse was important for eliciting the attack behavior of the rat. He stated that inactive mice sometimes elicited social, rather than aggressive, behavior from the rat, and that defensive maneuvers from the mouse might elicit or inhibit the rat's killing response.

To our knowledge, all previous studies involving a comparison of the rat's responses to different types of mice have utilized either different sexes or different strains of domestic mice. Our comparison involved animals that were much more dissimilar than mice previously compared. The results we obtained were startling in their clarity, i.e., WM were differentiated from DM either in terms of the rate of killing or the latency to kill, or both, in every experiment reported. The discrimination survived blinding, deafening, removal of the vibrissae, alte:ing the odor with a deodorant, altering the reactivity of the mouse, or combinations of treatments.

The original impetus for the research reported in this paper was the supposition that the use of different types of mice in testing the effects of brain damage on muricidal behavior might lead to different conclusions. The results of this report are not relevant to the original question since braindamaged animals were not tested. It is entirely possible that different strains of domestic mice would have little effect upon normal rats, but a great effect on lesioned rats. For example, if rats with septal damage were tested with very inactive mice, it is possible that a low rate of killing would be exhibited because the mouse would not elicit the rage response. On the other hand, a very active mouse might be more likely to elicit the rage pattern and be killed. Our results primarily demonstrate that mice that differ in a variety of stimulus characteristics have differential effects upon normal rats.

In the light of previous failures to find evidence for unisensory control of complex behavior patterns in animals (e.g., Watson, 1907), our approach to the problem of the rat's ability to differentiate WM and DM may seem unwise. However, there are vast differences between the learning of a complex maze and the killing of a mouse, not the least of which is the fact that the former involves a highly artificial situation, while the latter is considered to be a response, the potential for which is common to all rats and one which either occurs, or would occur, in the wild.

An instinct may be defined as a complex pattern of behavior common to all members of a species which is inherited and unlearned. By this definition, the muricidal response of the rat qualifies as an instinct, and, as such, may be amenable to the type of analysis successfully used by ethologists. The actual killing response of the rat, which most researchers have described as being stereotyped, may be considered an example of a fixed action pattern, i.e., the relatively unmodifiable part of the instinct comprised of a sequence of coordinated motor actions which appears without learning. The fixed action pattern is elicited by some aspect of the total environmental input which has been designated by ethologists as the sign stimulus or releasing stimulus. According to Hess (1965), instinctive behavior is emitted in response to only a few of the potential stimuli to which the animal is exposed. For example, in the classical analysis of the courtship behavior of the stickleback by Tinbergen (1951), territorial defensive responses were 
elicited ty the red color of the intruder's belly. Models having other colors were much less provoking than those with red bellies, even if they more closely resembled another stickleback. Similarly, the peck of a newly hatched gull chick is elicited by very simple properties of the parent's bill and movement (Hailman, 1969). With practice, the response becomes more accurate and is elicited by more precise characteristics of the parent.

By using only naive animals in our experiments, we felt that the behavior under study would most likely be elicited by only a limited range of stimuli. The emphasis we placed upon olfactory cues as being primarily involved was based upon the knowledge that the rat is a macrosmatic animal and upon the wealth of evidence indicating that vision, audition, and the vibrissal sense organs are not involved or are minimally involved in the elicitation of the killing response.

In summary, we found the following:-(1) Given a 24-h test period, virtually all naive Long-Evans rats will kill freshly captured wild Mus musculus, while only a limited number kill a docile strain of domestic mouse. To our knowledge, this is the first demonstration of the importance of the type of mouse in the elicitation of muricidal behavior. (2) Impairment of vision, audition, or the vibrissal organs, either singly or in combination, had no effect on the rats' ability to discriminate wild and domestic mice. (3) Experiment VII in the present series provided evidence for the involvement of olfaction in the discrimination.

\section{REFERENCES}

Ai herts, J. R., \& Friedman, M. I. Olfactory bulb removal but not anosmia increases emotionality and mouse-killing. Vuture. 1972, 238, 454.455

Al Berts. J. R. \& Galef, B. G., JR. Acute anosmia in the rat: A beharioral lest of a peripherally-induced olfactory deficit. Phisiology and Behavior, 1971, 6, 619-621.

Aronson. L. A. Hormones and reproductive behavior: Some phylugenctic considerations. In T. E. McGill (Ed.), Readings in anımal behavior. New York: Holt, Rinehart, \& Winstinl. 19) 5 .

Bandiek. R. J.. \& Chi, C. C. Effects of olfactory bulb removal on aggression: A reevaluation. Physiology and Behavior, $1472,8.207 .211$.

Bicute. N. M.. \& Eichelman, B. S., JR. Sensory alterations and aggressice behavior in the rat. Physiology and Behavior, $1972,8,4 \times 1.985$.

CAIN, D. P. The role of the ulfactory bulb in limbic mechanisms. Psichological Bulletin, 1974, 81, 654-671.

(jkegolke. S. E., d S Sith, D. E. Mouse-killing in the rat: Ifflects of sensory deficits on attack behaviour and stereotyped billug. Animal Behaviour, 1975, 23, 186-191.

Hallman. J. P. How an instinct is learned. Scientific American, 1969, 221, 98-106.

Hess, E. H. Ethology: An approach toward the complete analysis of behavior. In T. E. McGill (Ed.), Readings in cinimal hehavior. New York: Holt, Rinehart, \& Winstuil. 190,5.

Kak11, 1, 1! Norway rat's killing response to the white mouse: An experinental analysis. Behaviour, 1956, 10, 81-103.
KarLI, P. Róle des aftérences sensorielles dans le déclencheme:at du comportenent d'aggression in interspécitique rat-souris. Compti Rendu des Séances de la Société de Biologie, 1961. 155, 644-64to.

Knutson. J. F. Aggression as manipulable behavior. In J. F. Knutson (F.d.), The comtrol of aggression. Chicago: Aldine, 1973.

Kreiskotr, H. Some comments on the killing response behaviour of the rat. In S. Garattini, \& E. B. Sigg (Eds.), Aggressive behaviour. New York: Wiley, 1969.

Latham. E. E., \& Thorne, B. M. Septal damage and muricide: Effects of strain and handling. Physiology and Behavior. $1974,12,521-526$.

Malick, J. B. A behavioral comparison of three lesion-induced models of aggression in the rat. Physiology and Behavior. 1970, 5, 674-681.

Mast, M., Blanchard, R. J., \& Matsumoto, R. Stimulus control of predatory aggression. Bulletin of the Psychonomic Socicty, 1974, 4, 454-456.

Mayer, A. D., \& Rosenblatt, J. S. Olfactory basis for the delayed onset of maternal behavior in virgin female rats: Experiential effects. Joumal of Comparative and Physiologicul Psychology, 1975, 89. 701-710.

Miczek, K. A., \& Grossman, S. P. Effects of septal lesions on inter- and intraspecies aggression in rats. Journal of Comparative and Physiological Psychology, 1972, 79, 37-45.

MYER. J. S. Stimulus control of mouse-killing rats. Journal of Comparative and Physiological Psychology, 1964, 58, 112-117.

MYER, J. S. Experience and the stability of mouse killing by rats. Journal of Comparative and Physiological Psychology' 1971, 75, 264-268.

Sidman, M. Tactics of scientific research. New York: Basic Books. 1960.

Sieck, M. H., \& Baumbach, H. D. Differential effects of peripheral and central anosmia producing techniques on spontaneous behavior patterns. Physiology and Behavior. 1974, 13, 407.425.

Spector, S. A., \& Hull, E. M. Anosmia and mouse killing by rats: A non-olfactory role for the olfactory bulbs. Journul of Compurative and Physiological Psychology, 1972. 80, 354-356.

Thor, D. H., \& Ghiseldi, W. B. Suppression of mouse killing and apomorphine-induced social aggression in rats by local anesthesia of the mystacial vibrissae. Journal of Comparative and Physiological Psychology, 1975, 88, 40-46. (a)

ThOR, D. H., \& Ghiselli, W. B. Vibrissal anesthesia and suppression of irritable fighting in rats: A temporary duration of effect in experienced fighters. Physiological Psychology, 1975, 3. 1-3. (b)

Thorne, B. M., Aaron, M., \& Latham, E. E. Effects of olfactory bulb ablation upon emotionality and muricidal behavior in four rat strains. Journal of Comparative and Physiological Psychology, 1973, 84, 339-344.

Thorne, B. M., Aaron, M., \& Latham, E. E. Olfactory system damage in rats and emotional, muricidal, and rat pup killing behavior. Physiological Psychology, 1974, 2. 157-163.

Tinbergen, N. The study of instinct. London: Oxford University Press, 1951.

Van Hemel, P. E., \& Colucci, V. M. Effects of target movement on mouse-killing attack by rats. Journal of Comparative und Physiological Psychology, 1973, 85, 105-110.

Vocel, J. R., \& LEAF, R. C. Initiation of mouse killing in nonkiller rats by repeated pilocarpine treatment. Physiology and Behavior, 1972, 8, 421-424.

Warson, J. B. Kinaesthetic and organic sensations: Their role in the reactions of the white rat to the maze. Psychological Munogruphs, 1907, 8(Whole No. 33).

(Received for publicution November 25, 1975; revision accepted March 2, 1976.) 